\title{
Evo-Devo and the Evolution of Social Behavior: Brain Gene Expression Analyses in Social Insects
}

\author{
A.L. Toth ${ }^{1}$ AND G.E. RoBinson ${ }^{2}$ \\ ${ }^{1}$ Department of Entomology, Pennsylvania State University, University Park, Pennsylvania 16827; \\ ${ }^{2}$ Department of Entomology, Neuroscience Program, and Institute for Genomic Biology, \\ University of Illinois, Urbana-Champaign, Illinois 61820 \\ Correspondence: generobi@illinois.edu
}

\begin{abstract}
Studies of genes and social behavior, aided by new genomic resources, are coming of age. Here, we show how some of the insights that have emerged from research on the evolution of development (evo-devo) also provide a useful framework for studying the evolution of social behavior at the molecular level. These insights include co-opting old genes for new functions, phenotypic modularity, genetic tool kits, the importance of gene regulation in evolutionary change, and the influences of some genes over multiple timescales. We next outline a few differences between development and behavior that pose challenges for an evo-devo approach to behavior. For the remainder of this chapter, we review several studies that illustrate the relevance of evo-devo insights to our understanding of the evolution of behaviors related to eusociality in the insect societies.
\end{abstract}

A major goal in biology is to understand the evolution of complex traits, such as the development of animal body plans and social behavior. Studies of the molecular basis of development have led to a fruitful synthesis with evolutionary biology, giving rise to the hybrid field of evolutionary developmental biology, or "evo-devo" (Carroll et al. 2005). Evo-devo has had striking success in explaining how genetic changes generate diversity in form during evolution. In addition, some of the insights from evo-devo appear to be relevant for understanding the evolution of behavior at the molecular level, particularly naturally occurring behavior, which has been subjected to molecular analysis only relatively recently (Toth and Robinson 2007).

The molecular bases of learning and memory (Kandel 2007) and circadian behavior (Young and Kay 2001) have been intensively studied in the laboratory with model organisms for more than 25 years. These studies have drawn on mechanistic perspectives in cellular and neurobiology. In contrast, the study of naturally occurring behavior in nature - the type that is studied from both mechanistic and evolutionary perspectives - has embraced molecular analysis only in the past decade or so. Perhaps this was because it is much more difficult to wed molecular analysis with phenotypes studied in the field, rather than in the laboratory, especially with the traditional (pregenomic) tools of molecular biology. An additional difficulty for behavioral biology is that whereas morphological phenotypes are relatively stable, behavioral phenotypes are more changeable and fleeting, especially under natural conditions. This later start for field-based behavior has provided an opportunity to gain insights from evo-devo that are helpful in studying the evolution of behavior at the molecular level.

In this chapter, we first summarize ideas from evo-devo that can be applied to studies of the evolution of behavior at the molecular level. We next outline a few differences between development and behavior that pose challenges for evo-devo. For the remainder of this chapter, we review several studies that illustrate the relevance of evo-devo insights to our understanding of the evolution of behaviors related to eusociality in insect societies. We focus especially on evolutionary insights that have been gained from studies that use a key element of the evo-devo approach: gene expression analysis. We end by suggesting directions for future research in this area.

\section{EVO-DEVO AND EVOLUTIONARY MOLECULAR ANALYSES OF BEHAVIOR}

\section{Evo-devo Insights}

Several insights into the relationship between genes and complex phenotypes that have emerged from evodevo (Carroll et al. 2005) are also reflected in findings from evolutionary molecular analyses of behavior (for review, see Toth and Robinson 2007). We highlight five such insights and provide brief accounts of their relevance for behavior.

The first insight from evo-devo is that the original or ancestral function of a gene can be co-opted to generate a novel trait (True and Carroll 2002). For example, genes in the SCPP (secretory calcium-binding phosphoprotein) family, with ancestral functions mediating interactions between cells and the extracellular matrix, were co-opted to regulate the formation of vertebrate bones, teeth, and enamel (Sanetra et al. 2005). In behavior, several examples of genes related to solitary forms of behavior have been co-opted to support social behavior, as is discussed later.

The second insight from evo-devo pertains to the modular organization of body plans; diversity in form arises from molecular processes that result in adaptive special- 
ization of segments or appendages. Many morphological features can be dissected into distinct components, each repeated in series. These components can be added, deleted, or shuffled to create novel morphologies based on subtle changes in the timing and location of gene expression (Emlen et al. 2005; Brakefield 2006; Monteiro and Podlaha 2009). For example, variation in the expression of genes in the ectodysplasin pathway, part of a deeply conserved network of homeotic (Hox) genes, are associated with a wide array of dentition patterns in vertebrates (Fraser et al. 2009), and changes in this network have resulted in numerous adaptive gains, losses, and changes in the arrangement of teeth (Stock 2001).

Similar to the tooth example above, complex forms of behavior have been productively dissected into simpler "behavioral modules," and experimental approaches that begin with a deconstruction of behavior into component phenotypes have been successful. Ben-Shahar et al. (2004) discovered that malvolio, a gene related to sucrose responsiveness in Drosophila melanogaster, also affects the age at which honey bees (Apis mellifera) switch from working in the hive to foraging. malvolio was considered to be a candidate gene for this process because sucrose responsiveness was known to be a module of honey bee foraging behavior; an increase in sucrose responsiveness is associated with the onset of foraging (Rueppell et al. 2006). Sucrose responsiveness is just one of several modules of honey bee foraging, a complex multicomponent behavior that involves learning, communication, and changes in other sensory systems (Seeley 1995; Ben-Shahar et al. 2003).

The third insight from evo-devo is the notion of the genetic "tool kit" for development, i.e., a set of genes that perform highly conserved roles across diverse taxa, e.g., the Hox genes and their role in regulating body form (Gellon and McGinnis 1998) and the paired box (Pax) genes and their role in eye development (Pichaud and Desplan 2002). The genetic tool kit for development is thought to consist of a set of genes with highly specialized functions, especially transcription factors (Carroll et al. 2005). Similarly, there are now several cases of specific genes, pathways, or networks with conserved roles across species that are important in behavior. For example, serotonin influences aggressive behavior across a wide range of animals, from crustaceans to humans (Kravitz 2000; Lesch and Merschdorf 2000).

The fourth insight from evo-devo is the realization that many novel traits arise from evolutionary changes in gene expression (Wray 2007). It has long been known that changes in coding sequence also can be important for the evolution of novel traits (Hoekstra and Coyne 2008); evo-devo has in addition highlighted the lability of gene regulation as a major contributor to evolutionary change. Likewise, changes in gene expression - that affect timing, location, or overall levels of mRNA abundance-are receiving increasing attention for behavioral evolution (Khaitovich et al. 2006). For example, differences in brain distribution of the vasopressin receptor VlaR in male voles cause large species differences in affiliative pairbonding behavior (Lim et al. 2004).

The fifth insight from evo-devo is that certain genes can exert influences on morphological development over differ- ent timescales, e.g., both developmental and evolutionary timescales. For example, bone morphogenic factor 4 and calmodulin genes are involved in "real-time" beak development in birds, and they also have been selected upon during evolution to generate the wide variation in beak sizes found in Darwin's finches (Abzhanov et al. 2004, 2006). Likewise, FOXP2 is involved in the real-time development of speech capabilities in humans and apparently also has been selected upon during evolution to generate diverse forms of animal communication (Shu et al. 2005).

\section{Genetic Architectures for Developmental and Behavioral Traits}

Molecular and genetic analyses have revealed additional similarities between developmental and behavioral traits, further arguing for the relevance of evo-devo perspectives to behavior. Both behavioral and morphological phenotypes can have a wide range of heritability estimates, from almost zero to extremely high. Furthermore, the range of heritability estimates for both behavior and morphology overlap broadly (Hoffmann 2000). It is clear that some forms of behavior, as with morphological phenotypes, are highly heritable. This has long been seen in laboratory studies of behavior (Hoffmann 2000) and is now becoming apparent for naturally occurring behavior in the field as well (see, e.g., Dingemanse et al. 2002), including a variety of human behavioral traits (Bouchard and McGue 2003).

It also is well established in both development and behavior that certain single genes can have huge effects on phenotype. In development, a mutation in the antennapedia gene in Drosophila transforms the antennae into legs (Postlethwait and Schneiderman 1971). In behavior, a mutation in the fruitless gene causes male Drosophila to court other males (Baker et al. 2001). In addition to these induced mutations, there also are examples of similar large effects for naturally occurring developmental and behavioral variation. In species of stickleback fish (genus Gasterosteus), for example, allelic differences in regulatory regions of the Pitxl gene determine whether pelvic spines are present or absent (Shapiro et al. 2004). In Drosophila, natural allelic variation in the foraging gene leads to big differences in foraging behavior, resulting in either "sitter" or "rover" phenotypes (Osborne et al. 1997).

In addition to traits affected by single genes with major effects, both developmental and behavioral traits can have more complex genetic architectures. For example, Mackay and colleagues (for review, see Mackay 2009), using transcriptomic profiling of a large set of strains of Drosophila, reported that $20 \%-40 \%$ of the genes in the Drosophila genome are involved in the regulation of strain-specific differences in both morphological and behavioral traits.

\section{CHALLENGES TO THE EVO-DEVO APPROACH FOR BEHAVIOR}

Despite the above similarities, some notable differences between development and behavior pose challenges for the application of the evo-devo approach to behavior. Studies on the evolution of morphological novelty were 
initiated only after extensive knowledge was obtained on the mechanistic - genetic and cellular — bases of development, drawing on molecular analyses of model genetic species (Carroll et al. 2005). In contrast, molecular analyses of behavioral evolution are proceeding simultaneously with mechanistic analyses (Robinson et al. 2005) and thus do not benefit from a wealth of prior information, as did evo-devo studies.

Much is known about the neural substrates of behavior, but most of this knowledge is confined to laboratorybased behavioral systems (Carew 2000; Kandel et al. 2000). For naturally occurring behavior in the field, underlying mechanisms have not been as well studied; i.e., less is known about the ways in which circuits of neurons generate a behavior than the ways in which cells and tissues generate a morphological trait. This is no doubt because behavior is generated by the brain, an exceedingly complex organ with highly specialized subregions and patterns of cell connectivity. Because of the complexity of the brain, the mapping of genes to behavior via the brain is more of a mystery than the mapping of genes to morphological trait via cells and tissues.

Another difference between development and behavior relates to timescales. Behavioral change can occur much faster than developmental change, on a timescale that is faster than the rate of gene transcription. Orchestrating changes at this timescale involves the many posttranscriptional and posttranslational changes that occur in the brain, including release of neurotransmitters and the opening and closing of various ion channels. A complete explanation of the molecular basis of behavior and its evolution will require an understanding of how both genomic and neural mechanisms interact across different timescales, from the acute physiological timescale all the way to the evolutionary timescale.

Despite these challenges, perspectives from evo-devo can be applied productively to studies of the evolution of behavior at the molecular level. Moreover, we believe that molecular analyses of behavioral evolution can also help to fill the gap of knowledge on the neural basis of naturally occurring behavior. For example, analyses of the distribution of the vasopressin receptor VIaR gene in the brains of male monogamous and nonmonogamous vole species (Insel and Young 2001) led to discoveries linking vasopressin signaling to dopaminergic circuits related to reward processing in the mesolimbic "reward system" of the brain (Young and Wang 2004). Similar payoffs have occurred in studies of social insects, as can be seen in the following section.

\section{EVO-DEVO AND BEHAVIOR IN INSECT SOCIETIES}

\section{Eusociality}

Previous sections included brief examples from studies of different forms of behaviors in a variety of organisms that indicate that insights from evo-devo are readily applicable to studies of the evolution of behavior at the molecular level. In the next sections, we illustrate this point in greater detail by concentrating on one particular form of social behavior: eusociality in insects. We discuss the evolutionary insights that have been gained from studies of eusocial behavior that use a key element of the evodevo approach - a focus on gene expression analysis.

Eusociality in insects is emerging as a powerful system to study the mechanisms and evolution of social life in molecular terms (Robinson et al. 2005; Smith et al. 2008). Eusociality is a highly derived system of social organization. Eusociality in the Hymenoptera (ants, bees, and wasps) has evolved independently approximately 10 times (Brady et al. 2006; Hines et al. 2007), each time resulting in three convergent and defining traits: (1) a reproductive division of labor between queens and workers, (2) overlapping generations of individuals sharing a nest, and (3) individuals that care cooperatively for offspring that are not their own ("workers") (Wilson 1971). The behavior of many species of social insects is well understood at the ecological and evolutionary levels. Social insect behavior also is very amenable to considerable experimental manipulation, especially in terms of the ability to precisely manipulate the social environment and study its effects on individual colony members (Smith et al. 2008).

The examples we provide illustrate the evo-devo concepts described above, as follows.

1. Co-option: Genes involved in solitary behavior appear to have been co-opted for new functions in a social system.

2. Modularity: Molecular analyses have identified modules of solitary behavior as components of social behavior.

3. Genetic tool kit: Similar patterns of brain gene expression are associated with division of labor in independently evolved social insect lineages, supporting the idea of a tool kit for behavior in the social insects.

4. Timescales: Some of the same genes that are associated with behavioral differences on an evolutionary timescale (e.g., between strains of the same species) are also associated with behavioral differences on shorter timescales as well, within an individual's lifetime.

The remaining concept from above, a focus on gene expression, is implicit in our treatment of the other four concepts; i.e., the examples we provide have used gene expression analysis to derive insights into the evolution of eusocial behavior at the molecular level. A focus on gene expression might be particularly important for analyses of behavior in social insects (Robinson and Ben-Shahar 2002; Linksvayer and Wade 2005). Just as cells within an organism develop into distinct cell types on the basis of differential gene expression, individuals within a social insect colony develop into "castes" (queens and workers) that differ in both behavior and (sometimes) morphology (Wilson 1971); this also typically occurs on the basis of differential gene expression (Robinson et al. 2005). Several lines of research with social insects suggest that changes in gene regulation across several different timescales are important in the evolution of social behavior.

Co-option: Nutrition and division of labor for foraging. Genes involved in solitary forms of foraging behavior appear to have been co-opted for social foraging in 
honey bees. Evidence comes from studies of foraging and malvolio and genes in the insulin/insulin-like growth factor signaling (IIS) pathway.

Many basic forms of behavior, such as food gathering or foraging, seem to be similar between solitary and social bees-both collect pollen and nectar from flowers. However, there is a fundamental difference: A social bee's behavior is adapted to increase the fitness of its colony rather than its own personal fitness. This gives rise to important differences in when and how foraging is performed. Despite these differences, recent results suggest that genes associated with food gathering and eating in solitary insects have been co-opted to regulate social foraging in honey bees and other species of social insects.

In $D$. melanogaster, the foraging gene (for) encodes a cGMP-dependent protein kinase (protein kinase G [PKG]), and naturally occurring allelic variation in this gene results in two phenotypes: "sitters" and "rovers" (Osborne et al. 1997). Although D. melanogaster lives most of its life in solitary fashion, the behavioral variation associated with these allelic differences suggested an interesting parallel with the food-gathering behavior of the honey bee. Honey bees exhibit age-related changes in behavior; e.g., young bees work inside the hive (analogous to fly "sitters"), but as they age, they "rove" outside the hive in search of food.

An ortholog of Drosophila for was found to regulate this age-related change in behavior in honey bees. Levels of for mRNA in the bee brain are greater in foragers than in bees working in the hive, and experimentally activating PKG causes precocious foraging (Ben-Shahar et al. 2002). for expression is socially regulated in honey bees: Levels of for mRNA are also elevated in the brains of young bees induced to forage early in response to a lack of older bees (Ben-Shahar et al. 2002). cGMP signaling also affects feeding arousal in Caenorhabditis elegans (Fujiwara et al. 2002), and differences in the expression of for between foraging and nonforaging individuals have been reported in two ant species (Ingram et al. 2005; Lucas and Sokolowski 2009) and two wasp species (Tobback et al. 2008; AL Toth et al., in prep.), demonstrating the evolutionary lability of pathways involving PKG signaling.

$m v l$ encodes a manganese transporter, and a mutation at this locus in Drosophila causes a loss of responsiveness to sucrose; this deficit is eliminated by treatment with manganese (Rodrigues et al. 1995). As stated above, sucrose responsiveness is a behavioral module of foraging in honey bees (Pankiw and Page 1999); an increase in sucrose responsiveness is associated with the onset of foraging. Quantitative trait locus (QTL) analysis has revealed that the genetic architecture of sucrose responsiveness and onset age of foraging are related (Rueppell et al. 2006). These results suggested that $m v l$ also was a good candidate gene for the regulation of division of labor in honey bees. $m v l$ brain expression is higher in foragers than in bees working in the hive, and manganese treatment not only increased sucrose responsiveness, but also caused an earlier onset of foraging (Ben-Shahar et al. 2004). Food-deprived bees also show increased sucrose responsiveness (Ben-Shahar and Robinson 2001), suggesting important associations among foraging behavior, nutritional state, sucrose responsive- ness, and brain expression of $m l v$, as well as for other genes (Whitfield et al. 2006).

IIS genes are well known to affect feeding behavior in a wide variety of animals (Konturek et al. 2004). Ament et al. (2008) reported up-regulation of IIS genes in foragers (in brain and abdomen) relative to hive bees, and a delay in the shift from working in the hive to foraging induced by pharmacological inhibition of the TOR (target of rapamycin) pathway, which is related to IIS. Foragers have about half the lipid stores of hive bees, and a reduction in nutritional status can cause an early onset of foraging (Toth et al. 2005), indicating that high IIS is associated with low nutrient status in adult worker bees. This is opposite to what is found in larval honey bees (Wheeler et al. 2006) and opposite to the norm in other species (Ikeya et al. 2002). These results suggest evolutionary changes in the way IIS pathways are regulated across life stages and species. Measurements of IIS brain gene expression from Polistes metricus wasps also suggest an association between several IIS genes and lipid stores (Toth et al. 2007, 2009). In this species, there also is a causal association between reduced nutrient stores and foraging (TD Daugherty et al., unpubl.), suggesting that connections among nutrition, IIS signaling, and foraging in social insects might be widespread.

It thus appears that some well-conserved molecular pathways that influence food-gathering behavior in solitary insects such as Drosophila also regulate the division of labor in social insect societies. An important issue for the future is to address why certain feeding-related pathways, or components of these pathways, are more evolutionarily labile than others.

Modularity: Maternal behavior as a precursor to altruistic worker behavior. Comparative ethological analyses identified modules of solitary behavior as components of eusocial behavior more than 30 years ago (Evans and West-Eberhard 1973). Recent gene expression analyses have provided support for these ideas.

It is well established that the solitary ancestors to all social Hymenoptera were nesting wasps with well-developed maternal care (Evans and West-Eberhard 1973). The behavior of such a solitary maternal insect can be broken down into two distinct behavioral modules: (1) egg-laying and (2) maternal provisioning of brood with food collected during foraging. West-Eberhard proposed that an ancestral ovarian cycle consisting of these two basic modules of egg-laying and foraging/provisioning could be uncoupled during evolution (for review, see West-Eberhard 1996). Instead of being separated in time during the life of a solitary maternal wasp, the two behaviors could become so separated as to occur only in different individuals - "queens" that focus on egg-laying and "workers" that specialize in foraging/provisioning. In other words, worker behavior, which involves caring for siblings, may have evolved from maternal foraging/provisioning.

A molecular dimension was added to this idea with the prediction that sibling care and maternal care behaviors should be regulated by similar patterns of gene expression (Linksvayer and Wade 2005). This was tested in P. metricus wasps, a species that is well suited for evolutionary 
analyses because it is "primitively" eusocial and retains maternal behavior during the "foundress" part of its life cycle. Working with a set of 32 genes selected from microarray studies of honey bee division of labor (Whitfield et al. 2003, 2006), Toth et al. (2007) found the predicted relationship: Brain expression in worker wasps was more similar to the maternal foundresses than to queens, which do not show maternal care.

Putative ancestral modules of solitary foraging and reproduction may also have been involved in structuring various forms of division of labor among workers, which are thought to have evolved after the evolution of queens and workers (West-Eberhard 1996). As described above for honey bees, colonies of social insects often show a division of labor among young nest workers and old foragers, and although worker honey bees are mostly sterile, nest workers retain a higher reproductive capacity than foragers. When a colony of honey bees loses its queen, it is the younger workers that are more likely to begin laying (unfertilized) eggs (Winston 1987). Microarray results suggest that the brain gene expression profiles of hive bees are indeed more queen-like than those for foragers (Grozinger et al. 2007). In addition, bees that specialize on foraging for pollen have more well-developed ovaries and higher levels of expression of the egg yolk protein vitellogenin than do bees that specialize on foraging for nectar (Nelson et al. 2007). Thus, these two ancestral modules of foraging and reproduction may have been uncoupled multiple times during social insect evolution to produce the kinds of highly specialized individuals that characterize life in an insect society.

Tool kits: Shared patterns of gene expression across social insect lineages. The results discussed above (see section Co-option: Nutrition and division of labor for foraging), based on studies of small numbers of genes, suggest that genes related to feeding behavior may form the basis for one such tool kit for division of labor in social insects. This provides initial support for the idea of a tool kit for eusociality, i.e., core sets of genes used repeatedly during social evolution to generate novel forms of behavior (Toth and Robinson 2007). Additional evidence for this idea comes from more global studies of gene expression that explored whether the same pathways regulate different forms of division of labor in independently evolved social insect lineages.

Toth et al. (2007) provided initial evidence for this conclusion in the study of 32 genes in Polistes paper wasps described above. A large percentage $(63 \%)$ of these genes that showed differential brain expression in the context of honey bee division of labor behavior also showed differential expression in the context of wasp division of labor. This line of study has recently been expanded with the creation of a P. metricus microarray (AL Toth et al., in prep.), allowing comparison of large-scale paper wasp and honey bee transcriptomic profiles. In this study, patterns of brain gene expression were compared in four different female groups that comprise a paper wasp society: foundresses (nest initiators), queens, workers, and gynes (future queens in reproductive diapause). These four groups differ in terms of foraging/provisioning and reproductive activity; queens and foundresses reproduce while workers and foundresses forage and provision the brood. Nearly 200 genes were differentially expressed as a function of foraging/provisioning. A comparison of this list of genes with microarray-derived lists of genes associated with honey bee worker foraging behavior (Whitfield et al. 2006; Alaux et al. 2009) showed a significant overlap in global brain gene expression patterns for the two species despite the vastly different forms of division of labor (AL Toth et al., in prep.). Genes associated with division of labor in honey bees are likely associated with division of labor in wasps, thus providing initial support for the existence of a "genetic tool kit" for division of labor that is shared across independent eusocial lineages.

A comparison of the functional categories of genes that affect social phenotypes across a wide range of social insects suggests broad conservation. For example, AL Toth et al. (in prep.) also found that genes for lipid metabolism, locomotory behavior, and response to heat stress were overrepresented on the list of genes regulated in association with paper wasp foraging/ provisioning, and several genes in these same categories are also differentially regulated in other social insect species. Heat shock protein and metabolic genes are differentially expressed in several honey bee brain transcriptomic studies related to foraging (Whitfield et al. 2003, 2006; Ament et al. 2008; Alaux et al. 2009). Moreover, there are similarities with whole-body gene expression analyses of other social insect species. Polistes canadensis wasp queens and workers were found to differ in expression of vitellogenin, numerous metabolic enzymes, and a heat shock gene (Sumner et al. 2006). Graff et al. (2007) discovered queen-worker differences in vitellogenin expression in the ant Lasius niger. Caste-specific differences in hexamerin storage proteins during early development have been reported in a wide variety of species including yellow jackets, paper wasps, and termites (Scharf et al. 2005; Hoffman and Goodisman 2007; Hunt et al. 2007). These results also provide support for the idea that certain genes and pathways have been used repeatedly during the evolution of eusociality in insects.

Gene regulation across different timescales. Some of the same genes that are associated with behavioral differences on an evolutionary timescale are also associated with behavioral differences on shorter timescales as well. This is illustrated with a recent study of aggression in honey bees.

Honey bees use their notorious stinging behavior to defend their hives against predators, both large and small. All honey bee colonies respond aggressively when their colony is attacked, but there is striking variation in the intensity of their response. In docile colonies, only a few bees may respond, whereas in more aggressive colonies, the response may involve hundreds or even thousands of stinging individuals. Colony defense begins when "guard" bees detect a disturbance at the hive entrance and release alarm pheromone, which alerts the entire colony. Older bees (who mostly forage for nectar and pollen) are more likely to respond aggressively than younger bees, but a 
subset of the colony's older bees, "soldiers," are the first to seek out and attack an intruder. There also are inherited differences in honey bee aggression. Africanized honey bees (AHB) have spread throughout most of the New World after the introduction in 1957 of the African subspecies A.m. scutellata, causing deaths of humans and animals in some parts of their newly inhabited range due to massive stinging responses. AHB are much more aggressive than European subspecies (EHB).

Certain genes can exert influences on morphological development over different timescales as discussed above, e.g., both developmental and evolutionary timescales. Alaux et al. (2009) used this perspective to explore whether environmental influences on a behavioral phenotype could have evolved into inherited differences via changes in gene regulation. One indication of this would be similar patterns of brain gene expression associated with aggression across the three timescales: acute (alarm pheromone exposure); life span (old vs. young), and evolutionary (AHB vs. EHB).

Alaux et al. (2009) found expression differences in the brain for hundreds of genes in the highly aggressive AHB compared to EHB. Similar results were obtained for EHB in response to exposure to alarm pheromone and when comparing old and young bees. Moreover, there was significant overlap of the gene lists generated from these three microarray experiments, thus supporting Waddington's (1959) genetic assimilation concept (phenotypic responses to environmental conditions can become encoded genetically) and suggesting that one element in the evolution of different degrees of aggressive behavior in honey bees involved changes in regulation of genes that mediate the response to alarm pheromone.

\section{CONCLUSIONS}

Studies of genes and social behavior, aided by new genomic resources, are coming of age, and social insects are good models for studying the evolution of social behavior at the molecular level. The relevance of some of the major insights from evo-devo suggests that using these insights to frame future studies will become increasingly fruitful. As genomic resources - including whole-genome sequencing - become more widely available, a broader array of species can be studied in this way (Hudson 2008), thus increasing the power of future comparative analyses. Well-resolved phylogenies are needed in order to carefully choose species that are both compelling in terms of social behavior and informative in a phylogenetic context, such as species in basal lineages or species that appear to have evolved similar behaviors independently.

The studies reviewed here relied extensively on transcriptomics, but other methods of molecular and genetic analysis are being used to study social behavior, in social insects and other species (Robinson et al. 2005, 2008; Page and Amdam 2007; Smith et al. 2008). Systems biology should prove to be increasingly important, allowing researchers to integrate different types of molecular information such as transcriptomics, proteomics, metabolomics, and epigenomics in order to develop models of regulatory networks (Robinson et al. 2008). Such integration will be necessary to better understand in molecular terms how various forms of behaviors evolve. Early indications suggest that, as for evo-devo, evolutionary molecular analyses of behavior have a bright future.

\section{ACKNOWLEDGMENTS}

We thank Sean B. Carroll and Trudy F.C. Mackay for comments that improved this manuscript. Research performed by the authors was supported by National Science Foundation Frontiers in Biological Research grant EF0425852 (B.R. Schatz, PI), the Illinois Sociogenomics Initiative, NIH-DC 006395, USDA-NRI 2004-3560414277, NSF IOS 06-41431 (G.E.R), and a USDA-NRI postdoctoral fellowship (A.L.T.).

\section{REFERENCES}

Abzhanov A, Protas M, Grant BR, Grant PR, Tabin CJ. 2004. Bmp 4 and morphological variation of beaks in Darwin's finches. Science 305: 1462-1465.

Abzhanov A, Kuo WP, Hartmann C, Grant BR, Grant PR, Tabin CJ. 2006. The calmodulin pathway and evolution of elongated beak morphology in Darwin's finches. Nature 442: 563-567.

Alaux C, Sinha S, Hasadsri L, Hunt GJ, Guzman-Novoa E, DeGrandi-Hoffman G, Uribe-Rubio JL, Rodriguez-Zas SL, Robinson GE. 2009. Honey bee brain gene expression supports a link between cis regulation and behavioral evolution. Proc Natl Acad Sci 106: 15400-15405.

Ament SA, Corona M, Pollock HS, Robinson GE. 2008. Insulin signaling is involved in the regulation of worker division of labour in honey bee colonies. Proc Natl Acad Sci 105: 42264231.

Baker BS, Taylor BJ, Hall JC. 2001. Are complex behaviors specified by dedicated regulatory genes? Reasoning from Drosophila. Cell 105: 13-24.

Ben-Shahar Y, Robinson GE. 2001. Satiation differentially affects performance in a learning assay by nurse and forager honey bees. J Comp Physiol A 187: 891-899.

Ben-Shahar Y, Robichon A, Sokolowski MB, Robinson GE. 2002. Influence of gene action across different time scales on behavior. Science 296: 741-744.

Ben-Shahar Y, Leung H-T, Pak WL, Sokolowski MB, Robinson GE. 2003. cGMP-dependent changes in phototaxis: A possible role for the foraging gene in honey bee division of labor. $J$ Exp Biol 206: 2507-2515.

Ben-Shahar Y, Dudek NL, Robinson GE. 2004. Phenotypic deconstruction reveals involvement of manganese transporter malvolio in honey bee division of labor. J Exp Biol 207: 3281-3288.

Bouchard TJ, McGue M. 2003. Genetic and environmental influences on human psychological differences. J Neurobiol 54: 4-45.

Brady SG, Sipes S, Pearson A, Danforth BN. 2006. Recent and simultaneous origins of eusociality in halictid bees. Proc $R$ Soc Lond B Biol Sci 273: 1643-1649.

Brakefield PM. 2006. Evo-devo and constraints on selection. Trends Ecol Evol 21: 362-368.

Carew TJ. 2000. Behavioral neurobiology: The cellular organization of natural behavior. Sinauer Associates, Sunderland, MA.

Carroll SB, Grenier J, Weatherbee S. 2005. From DNA to diversity: Molecular genetics and the evolution of animal design. Wiley-Blackwell, Hoboken, NJ.

Dingemanse NJ, Both C, Drent PJ, Van Oers K, Van Noordwijk AJ. 2002. Repeatability and heritability of exploratory behaviour in great tits from the wild. Anim Behav 64: 929-938.

Emlen DJ, Hunt J, Simmons LW. 2005. Evolution of sexual dimorphism and male dimorphism in the expression of beetle horns: Phylogenetic evidence for modularity, evolutionary 
lability, and constraint. Am Nat 166: S42-S68.

Evans HE, West-Eberhard MJ. 1973. The wasps. David and Charles, Newton Abbott, United Kingdom.

Fraser GJ, Hulsey CD, Bloomquist RF, Uyesugi K, Manley NR, Streelman JT. 2009. An ancient gene network is co-opted for teeth on old and new jaws. PLoS Biol 7: e1000031.

Fujiwara M, Sengupta P, McIntire SL. 2002. Regulation of body size and behavioral state of $C$. elegans by sensory perception and the EGL-4 cGMP-dependent protein kinase. Neuron 36: 1091-1102.

Gellon G, McGinnis W. 1998. Shaping animal body plans in development and evolution by modulation of Hox expression patterns. BioEssays 20: 116-125.

Graff J, Jemielity S, Parker JD, Parker KM, Keller L. 2007. Differential gene expression between adult queens and workers in the ant Lasius niger. Mol Ecol 16: 675-683.

Grozinger CM, Fan Y, Hoover SE, Winston ML. 2007. Genomewide analysis reveals differences in brain gene expression patterns associated with caste and reproductive status in honey bees (Apis mellifera). Mol Ecol 16: 4837-4848.

Hines HM, Hunt JH, O'Connor TK, Gillespie JJ, Cameron SA. 2007. Multigene phylogeny reveals eusociality evolved twice in vespid wasps. Proc Natl Acad Sci 104: 3295-3299.

Hoekstra HE, Coyne JA. 2008. The locus of evolution: Evo devo and the genetics of adaptation. Evolution 61: 995-1016.

Hoffman EA, Goodisman MAD. 2007. Gene expression and the evolution of phenotypic diversity in social wasps. BMC Biol 5: 23.

Hoffmann AA. 2000. Laboratory and field heritabilities: Some lessons from Drosophila. In Adaptive genetic variation in the wild (ed. TA Mousseau et al.), pp. 200-218. Oxford University Press, New York.

Hudson ME. 2008. Sequencing breakthroughs for genomic ecology and evolutionary biology. Mol Ecol Resour 8: 3-17.

Hunt JH, Kensinger BJ, Kossuth JA, Henshaw MT, Norberg K, Wolschin F, Amdam GV. 2007. A diapause pathway underlies the gyne phenotype in Polistes wasps, revealing an evolutionary route to caste-containing insect societies. Proc Natl Acad Sci 104: 14020-14025.

Ikeya T, Galic M, Belawat P, Nairz K, Hafen E. 2002. Nutrientdependent expression of insulin-like peptides from neuroendocrine cells in the CNS contributes to growth regulation in Drosophila. Curr Biol 12: 1293-1300.

Ingram KK, Oefner P, Gordon DM. 2005. Task-specific expression of the foraging gene in harvester ants. Mol Ecol 14: 813818.

Insel TR, Young LJ. 2001. The neurobiology of attachment. Nat Rev Neurosci 2: 129-136.

Kandel ER. 2007. In search of memory: The emergence of a new science of mind. W.W. Norton, New York.

Kandel ER, Harris Schwartz J, Jessell TM. 2000. Principles of neural science. Appleton and Lange, Norwalk, CT.

Khaitovich P, Tang K, Franz H, Kelso J, Hellmann I, Enard W, Lachmann M, Paabo S. 2006. Positive selection on gene expression in the human brain. Curr Biol 16: R356-R358.

Konturek SJ, Konturek JW, Pawlik T, Brzozowki T. 2004. Braingut axis and its role in the control of food intake. $J$ Physiol Pharmacol 55: 137-154.

Kravitz EA. 2000. Serotonin and aggression: Insights gained from a lobster model system and speculations on the role of amine neurons in a complex behavior. J Comp Physiol A 186: 221-238.

Lesch KP, Merschdorf U. 2000. Impulsivity, aggression, and serotonin: A molecular psychobiological perspective. Behav Sci Law 18: 581-604.

Lim MM, Wang Z, Olazábal DE, Ren X, Terwilliger EF, Young LJ. 2004. Enhanced partner preference in a promiscuous species by manipulating the expression of a single gene. Nature 429: 754-757.

Linksvayer TA, Wade MJ. 2005. The evolutionary origin and elaboration of sociality in the aculeate Hymenoptera: Maternal effects, sib-social effects, and heterochrony. Q Rev Biol 80: 317-336.
Lucas C, Sokolowski MB. 2009. Molecular basis for changes in behavioural state in ant social behaviours. Proc Natl Acad Sci 106: 6351-6356.

Mackay TFC. 2009. The genetic architecture of complex behaviors: Lessons from Drosophila. Genetica 136: 295-302.

Monteiro A, Podlaha O. 2009. Wings, horns, and butterfly eyespots: How do complex traits evolve? PLoS Biol 7: e100003.

Nelson M, Ihle K, Fondrk MK, Page RE, Amdam GV. 2007. The gene vitellogenin has multiple coordinating effects on social organization. PLoS Biol 5: e62.

Osborne KA. Robichon A, Burgess E, Butland S, Shaw RA, Coulthard A, Pereira HS, Greenspan RJ, Sokolowski MB. 1997. Natural behavior polymorphism due to a cGMP-dependent protein kinase of Drosophila. Science 277: 834-836.

Page RE, Amdam GV. 2007. The making of a social insect: Developmental architectures of social design. BioEssays 29: 334-343.

Pankiw T, Page RE. 1999. The effect of genotype, age, sex, and caste on response thresholds to sucrose and foraging behavior of honey bees (Apis mellifera L.). J Comp Physiol A 185: 207 213.

Pichaud F, Desplan C. 2002. Pax genes and eye organogenesis. Curr Opin Genet Dev 12: 430-434.

Postlethwait JH, Schneiderman HA. 1971. Pattern formation and determination in the antenna of the homoeotic mutant Antennapedia of Drosophila melanogaster. Dev Biol 25: 606-640.

Robinson GE, Ben-Shahar Y. 2002. Social behavior and comparative genomics: New genes or new gene regulation? Genes Brain Behav 1: 197-203.

Robinson GE, Grozinger CM, Whitfield CW. 2005. Sociogenomics: Social life in molecular terms. Nat Rev Genet 6: 257-270.

Robinson GE, Fernald RD, Clayton DF. 2008. Genes and social behavior. Science 322: 896-900.

Rodrigues V, Cheah PY, Ray K, Chia W. 1995. malvolio, the Drosophila homolog of house Nramp-1 (Bcg), is expressed in macrophages and in the nervous system and is required for normal taste behavior. EMBO J 14: 3007-3020.

Rueppell O, Chandra SB, Pankiw T, Fondrk MK, Beye M, Hunt G, Page RE. 2006. The genetic architecture of sucrose responsiveness in the honeybee (Apis mellifera L.). Genetics 172: 243-251.

Sanetra M, Begemann G, Becker M-B, Meyer A. 2005. Conservation and co-option in developmental programmes: The importance of homology relationships. Front Zool 2: 15.

Scharf ME, Wu-Scharf D, Zhou X, Pittendrigh BR, Bennett GW. 2005. Gene expression profiles among immature and adult reproductive castes of the termite Reticulitermes flavipes. Insect Mol Biol 14: 31-34.

Seeley TD. 1995. The wisdom of the hive. Harvard University Press, Cambridge, MA.

Shapiro MD, Marks ME, Peichel CL, Blackman BK, Nereng KS, Jónsson B, Schluter D, Kingsley DM. 2004. Genetic and developmental basis of evolutionary pelvic reduction in threespine sticklebacks. Nature 428: 717-723.

Shu W, Cho JY, Jiang Y, Zhang M, Weisz D, Elderd GA, Schmeidlerd J, De Gasperi R, Gama Sosa MA, Rabidou D, et al. 2005. Altered ultrasonic vocalization in mice with a disruption in the Foxp2 gene. Proc Natl Acad Sci 102: 9643-9648.

Smith CR, Toth AL, Suarez AV, Robinson GE. 2008. Genetic and genomic analyses of the division of labour in insect societies. Nat Rev Genet 9: 735-748.

Stock DW. 2001. The genetic basis of modularity in the development and evolution of the vertebrate dentition. Philos Trans $R$ Soc Lond B Biol Sci 356: 1633-1656.

Sumner S, Pereboom JJ, Jordan WC. 2006. Differential gene expression and phenotypic plasticity in behavioural castes of the primitively eusocial wasp, Polistes canadensis. Proc $R$ Soc Lond B Biol Sci 273: 19-26.

Tobback J, Heylen K, Gobin B, Wenseleers T, Billen J, Arckens L, Huybrechts R. 2008. Cloning and expression of $P K G$, a candidate foraging regulating gene in Vespula vulgaris. Anim Biol 58: 341-351. 
Toth AL, Robinson GE. 2007. Evo-devo and the evolution of social behavior. Trends Genet 23: 334-341.

Toth AL, Kantarovich S, Meisel AF, Robinson GE. 2005. Nutritional status influences socially regulated foraging ontogeny in honey bees. J Exp Biol 208: 4641-4649.

Toth AL, Varala K, Newman TC, Miguez FE, Hutchison SK, Willoughby DA, Simons JF, Egholm M, Hunt JH, Hudson ME, et al. 2007. Wasp gene expression supports an evolutionary link between maternal behaviour and eusociality. Science 318: $441-444$.

Toth AL, Bilof KJ, Henshaw MT, Hunt JH, Robinson GE. 2009. Lipid stores, ovary development, and brain gene expression in Polistes metricus females. Insect Soc 56: 77-84.

True JR, Carroll SB. 2002. Gene co-option in physiological and morphological evolution. Annu Rev Cell Dev Biol 18: 53-80.

Waddington $\mathrm{CH}$. 1959. Canalization of development and genetic assimilation of acquired characters. Nature 183: 1654 1655.

West-Eberhard MJ. 1996. Wasp societies as microcosms for the study of development and evolution. In Natural history and evolution of paper wasps (ed. S Turillazzi and MJ West-
Eberhard), pp. 290-317. Oxford University Press, New York. Wheeler DE, Buck N, Evans JD. 2006. Expression of insulin pathway genes during the period of caste determination in the honey bee, Apis mellifera. Insect Mol Biol 15: 597-602.

Whitfield CW, Cziko A-M, Robinson GE. 2003. Gene expression profiles in the brain predict behaviour in individual honey bees. Science 302: 296-299.

Whitfield CW, Ben-Shahar Y, Brillet C, Leoncini I, Crauser D, LeConte Y, Rodriguez-Zas S, Robinson GE. 2006. Genomic dissection of behavioral maturation in the honey bee. Proc Natl Acad Sci 103: 16068-16075.

Wilson EO. 1971. The insect societies. Belknap/Harvard University Press, Cambridge, MA.

Winston ML. 1987. The biology of the honey bee. Harvard University Press, Cambridge, MA.

Wray GA. 2007. The evolutionary significance of cis-regulatory mutations. Nat Rev Genet 8: 206-216.

Young MW, Kay SA. 2001. Time zones: A comparative genetics of circadian clocks. Nat Rev Genet 2: 702-715.

Young LJ, Wang ZX. 2004. The neurobiology of pair bonding. Nat Neurosci 7: 1048-1054. 


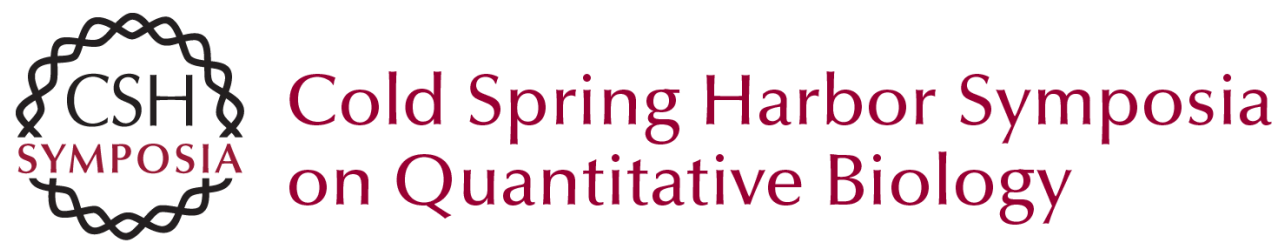

\title{
Evo-Devo and the Evolution of Social Behavior: Brain Gene Expression Analyses in Social Insects
}

\author{
A.L. Toth and G.E. Robinson \\ Cold Spring Harb Symp Quant Biol 2009 74: 419-426 originally published online October 22, 2009 \\ Access the most recent version at doi:10.1101/sqb.2009.74.026
}

References This article cites 67 articles, 16 of which can be accessed free at: http://symposium.cshlp.org/content/74/419.full.html\#ref-list-1

\section{License}

Email Alerting Service top right corner of the article or click here.

To subscribe to Cold Spring Harbor Symposia on Quantitative Biology go to: http://symposium.cshlp.org/subscriptions 